\title{
Chemical differentiation of the Earth: the relationship between mantle, continental crust, and oceanic crust
}

\author{
Albrecht W. Hofmann \\ Max-Planck-Institut für Chemie, Postfach 3060, 6500 Mainz (F.R.G.) \\ Received January 11, 1988; revised version accepted July 11, 1988
}

\begin{abstract}
The average chemical compositions of the continental crust and the oceanic crust (represented by MORB), normalized to primitive mantle values and plotted as functions of the apparent bulk partition coefficient of each element, form surprisingly simple, complementary concentration patterns. In the continental crust, the maximum concentrations are on the order of 50 to 100 times the primitive-mantle values, and these are attained by the most highly incompatible elements $\mathrm{Cs}, \mathrm{Rb}, \mathrm{Ba}$, and $\mathrm{Th}$. In the average oceanic crust, the maximum concentrations are only about 10 times the primitive mantle values, and they are attained by the moderately incompatible elements $\mathrm{Na}, \mathrm{Ti}, \mathrm{Zr}$, $\mathrm{Hf}, \mathrm{Y}$ and the intermediate to heavy REE.

This relationship is explained by a simple, two-stage model of extracting first continental and then oceanic crust from the initially primitive mantle. This model reproduces the characteristic concentration maximum in MORB. It yields quantitative constraints about the effective aggregate melt fractions extracted during both stages. These amount to about $1.5 \%$ for the continental crust and about $8-10 \%$ for the oceanic crust.

The comparatively low degrees of melting inferred for average MORB are consistent with the correlation of $\mathrm{Na}_{2} \mathrm{O}$ concentration with depth of extrusion [1], and with the normalized concentrations of $\mathrm{Ca}, \mathrm{Sc}$, and $\mathrm{Al}(\simeq 3)$ in $\mathrm{MORB}$, which are much lower than those of $\mathrm{Zr}, \mathrm{Hf}$, and the $\mathrm{HREE}(\approx 10) . \mathrm{Ca}, \mathrm{Al}$ and $\mathrm{Sc}$ are compatible with clinopyroxene and are preferentially retained in the residual mantle by this mineral. This is possible only if the aggregate melt fraction is low enough for the clinopyroxene not to be consumed.

A sequence of increasing compatibility of lithophile elements may be defined in two independent ways: (1) the order of decreasing normalized concentrations in the continental crust; or (2) by concentration correlations in oceanic basalts. The results are surprisingly similar except for $\mathrm{Nb}, \mathrm{Ta}$, and $\mathrm{Pb}$, which yield inconsistent bulk partition coefficients as well as anomalous concentrations and standard deviations.

The anomalies can be explained if $\mathrm{Nb}$ and $\mathrm{Ta}$ have relatively large partition coefficients during continental crust production and smaller coefficients during oceanic crust production. In contrast, $\mathrm{Pb}$ has a very small coefficient during continental crust production and a larger coefficient during oceanic crust production. This is the reason why these elements are useful in geochemical discrimination diagrams for distinguishing MORB and OIB on the one hand from island arc and most intracontinental volcanics on the other.

The results are consistent with the crust-mantle differentiation model proposed previously [2]. $\mathrm{Nb}$ and $\mathrm{Ta}$ are preferentially retained and enriched in the residual mantle during formation of continental crust. After separation of the bulk of the continental crust, the residual portion of the mantle was rehomogenized, and the present-day internal heterogeneities between MORB and OIB sources were generated subsequently by processes involving only oceanic crust and mantle. During this second stage, $\mathrm{Nb}$ and $\mathrm{Ta}$ are highly incompatible, and their abundances are anomalously high in both OIB and MORB.

The anomalous behavior of $\mathrm{Pb}$ causes the so-called "lead paradox", namely the elevated $\mathrm{U} / \mathrm{Pb}$ and $\mathrm{Th} / \mathrm{Pb}$ ratios (inferred from $\mathrm{Pb}$ isotopes) in the present-day, depleted mantle, even though $\mathrm{U}$ and $\mathrm{Th}$ are more incompatible than $\mathrm{Pb}$ in oceanic basalts. This is explained if $\mathrm{Pb}$ is in fact more incompatible than $\mathrm{U}$ and $\mathrm{Th}$ during formation of the continental crust, and less incompatible than $\mathrm{U}$ and Th during formation of oceanic crust.
\end{abstract}

\section{Introduction}

The isotopic evidence from the Earth's crust and mantle discussed elsewhere in this volume [3] has been decisive in establishing beyond reasonable doubt that the continental and oceanic crusts are chemically and isotopically complementary in many respects. On this basis, a generally accepted geochemical paradigm has emerged: formation of the continental crust has depleted a large part of the mantle in many incompatible trace elements, and this depleted part of the mantle is now the 
source of the oceanic crust. The continental crust has a mean age of about $2 \times 10^{9}$ years, roughly half the age of the Earth, whereas the oceanic crust is rapidly recycled into the mantle and has a mean life time of only about $10^{8}$ years or a fiftieth of the age of the Earth.

The isotopic data were corroborated qualitatively by the relative abundances of trace elements found in continental rocks and in MORB. For example the complementary pattern of high ${ }^{143} \mathrm{Nd} /{ }^{144} \mathrm{Nd}$ in MORB and low ${ }^{143} \mathrm{Nd} /{ }^{144} \mathrm{Nd}$ in continental rocks is matched by $\mathrm{Sm} / \mathrm{Nd}$ ratios which are high in MORB and low in continental rocks. Because of such correlations, it has become common practice to use trace element concentration ratios analogously to isotopic ratios to "fingerprint" crustal and mantle source reservoirs of volcanic rocks.

In this paper I examine the overall chemistry of crust and mantle in a rough but quantitative manner, in order to test and extend the inferences made from isotopic studies of very few trace elements. The result is a surprisingly simple and consistent pattern of complementary enrichment and depletion for nearly all lithophile elements for which there are analytical data. This pattern is adequately explained by a simple two-stage extraction model of continental and oceanic crust from an initially primitive mantle. This global crust-mantle differentiation was not, however, the primary process that generated the present-day, intra-oceanic mantle heterogeneities.

\section{Element abundance patterns}

Table 1 lists the abundances of 39 major and trace elements in the Earth's primitive mantle (also often called bulk silicate Earth), the continental crust, and average normal mid-ocean ridge basalts (usually called N-type MORB). These data are taken from the recent literature ([4-17], and footnote Table 1). The MORB data [4] were determined for a set of 26 MORB glasses selected for freshness rather than for being truly representative of a global average, and they may therefore be affected by sampling bias. The REE abundances in this average are significantly higher than those given by Sun et al. [5]. However, the averages shown by Sun et al. are based on a set of samples which is believed to be biased toward high melt fractions, for reasons given in section 4.1.

Klein and Langmuir [1] have shown that $\mathrm{Na}_{2} \mathrm{O}$ concentrations in MORB are well correlated with the depths of the axial valley floors of the spreading ridges. This correlation is global and provides a test for possible sampling bias of the present set of data, because the global coverage of bathymetry data is far more extensive than the coverage of dredged basalts extruded at the ridges. For the data set of Klein and Langmuir [1], the average depth of 27 ridge segments, each over $500 \mathrm{~km}$ long, and totalling about a quarter of the global ridge length, is about $3000 \mathrm{~m}$. A revised estimate of the global oceanic depth versus sea-floor age has recently been published [18], and this yields an extrapolated mean zero-age depth of $2700 \mathrm{~m}$. Actual depths of axial valley floors tend to be deeper than extrapolated zero-age depths, and the global mean depth of the axial valley is estimated to be $3000 \pm 300 \mathrm{~m}$. The mean fractionation-corrected $\mathrm{Na}_{2} \mathrm{O}$ concentration, interpolated at a depth of $3000 \mathrm{~m}$ from Klein and Langmuir's fig. 2d [1] is about $2.4 \pm 0.2 \%$, which is similar to the mean of our (identically corrected) $\mathrm{Na}_{2} \mathrm{O}$ concentrations of $2.53( \pm 0.08) \%$ and only slightly lower than the mean of our uncorrected $\mathrm{Na}_{2} \mathrm{O}$ concentrations of $2.68( \pm 0.07) \%$. The averages of $\mathrm{FeO}=10.4 \%$, $\mathrm{MgO}=7.6 \%$ and $\mathrm{CaO} / \mathrm{Al}_{2} \mathrm{O}_{3}=0.74$ given in Table 1 are also reasonably similar to the averages $\left(\mathrm{FeO}=9.2 \%, \quad \mathrm{MgO} \equiv 8.0 \%, \quad \mathrm{CaO} / \mathrm{Al}_{2} \mathrm{O}_{3}=0.76\right)$ inferred from the data of Klein and Langmuir. This indicates that the average composition of our sample set is within $10 \%$ of the true MORB average. These differences are small enough, so that they may be neglected for the purpose of the present paper.

\subsection{Compatibility sequence and general proper-} ties of the MORB pattern

Fig. 1 shows normalized element concentration patterns of average continental crust and average MORB, plotted in the order of decreasing continental abundances (from [17]). The concentrations are normalized by dividing each through the respective concentration in the primitive mantle. The rationale for using the order of continental concentrations to determine the sequence of elements plotted is that the degree of enrichment of an element in the continental crust is one possible 
TABLE 1

Major and trace element abundances in the Earth's primitive mantle, the continental crust and MORB

\begin{tabular}{|c|c|c|c|c|c|c|c|}
\hline \multirow[t]{2}{*}{ Element } & \multirow{2}{*}{$\begin{array}{l}\text { Primitive } \\
\text { mantle }\end{array}$} & \multicolumn{3}{|l|}{ MORB } & \multicolumn{3}{|c|}{ Estimated bulk continental crust } \\
\hline & & $\begin{array}{l}\text { N-MORB } \\
\text { avg. (n) }\end{array}$ & $\begin{array}{l}\text { N-MORB } \\
\text { normalized }\end{array}$ & $\begin{array}{l}\text { percent } \\
\text { std. dev. }\end{array}$ & TM1 & $\begin{array}{l}\text { TM1 } \\
\text { normalized }\end{array}$ & $\begin{array}{l}\text { TM2 } \\
\text { normalized }\end{array}$ \\
\hline $\mathrm{SiO}_{2}(\%)$ & 45.96 & 50.45 & 1.098 & 1.8 & 57.3 & 1.247 & 1.262 \\
\hline $\mathrm{Al}_{2} \mathrm{O}_{3}$ & 4.06 & 15.255 & 3.757 & 8.0 & 15.9 & 3.916 & 4.433 \\
\hline $\mathrm{FeO}$ & 7.54 & 10.426 & 1.383 & 14.8 & 9.1 & 1.207 & 0.995 \\
\hline $\mathrm{MgO}$ & 37.78 & 7.576 & 0.201 & 12.2 & 5.3 & 0.140 & 0.093 \\
\hline $\mathrm{CaO}$ & 3.21 & 11.303 & 3.521 & 7.2 & 7.4 & 2.305 & 2.336 \\
\hline $\mathrm{Na}_{2} \mathrm{O}$ & 0.332 & 2.679 & 8.070 & 13.3 & 3.1 & 9.337 & 10.542 \\
\hline $\mathrm{Na}_{2} \mathrm{O}(\mathrm{MgO}=8.0 \%)$ & 0.332 & 2.526 & 7.608 & 15.2 & & & \\
\hline $\mathrm{TiO}_{2}$ & 0.181 & 1.615 & 8.925 & 34.0 & 0.901 & 4.978 & 4.420 \\
\hline $\mathrm{La}(\mathrm{ppm})$ & 0.6139 & 3.895 & 6.345 & 41.4 & 16 & 26.06 & 30.95 \\
\hline $\mathrm{Ce}$ & 1.6011 & 12.001 & 7.496 & 40.1 & 33 & 20.61 & 23.73 \\
\hline $\operatorname{Pr}$ & 0.2419 & 2.074 & 8.574 & 39.0 & 3.9 & 16.12 & 17.78 \\
\hline $\mathrm{Nd}$ & 1.1892 & 11.179 & 9.401 & 37.8 & 16 & 13.45 & 13.45 \\
\hline $\mathrm{Sm}$ & 0.3865 & 3.752 & 9.708 & 37.0 & 3.5 & 9.06 & 9.57 \\
\hline $\mathrm{Eu}$ & 0.1456 & 1.335 & 9.167 & 30.1 & 1.1 & 7.56 & 7.56 \\
\hline $\mathrm{Gd}$ & 0.5128 & 5.077 & 9.901 & 36.5 & 3.3 & 6.44 & 7.02 \\
\hline $\mathrm{Tb}$ & 0.0940 & 0.885 & 9.412 & 38.1 & 0.60 & 6.38 & 6.81 \\
\hline Dy & 0.6378 & 6.304 & 9.884 & 34.5 & 3.7 & 5.81 & 5.80 \\
\hline Ho & 0.1423 & 1.342 & 9.433 & 36.6 & 0.78 & 5.48 & 5.76 \\
\hline Er & 0.4167 & 4.143 & 9.944 & 34.3 & 2.2 & 5.28 & 5.52 \\
\hline Tm & 0.0643 & 0.621 & 9.663 & 34.7 & 0.32 & 4.98 & 4.98 \\
\hline $\mathrm{Yb}$ & 0.4144 & 3.900 & 9.411 & 33.8 & 2.2 & 5.31 & 5.31 \\
\hline $\mathrm{Lu}$ & 0.0637 & 0.589 & 9.246 & 33.8 & 0.30 & 4.71 & 4.71 \\
\hline $\mathrm{K}$ & 258.2 & 883.7 & 3.422 & 46.0 & 9100 & 35.24 & 48.41 \\
\hline $\mathrm{Rb}$ & 0.5353 & 1.262 & 2.357 & 76.2 & 32 & 59.78 & 78.46 \\
\hline $\mathrm{Cs}$ & $(0.0268)$ & 0.01408 & $(0.53)$ & 71.9 & 1.0 & $(37.3)$ & $(63.43)$ \\
\hline $\mathrm{Sr}$ & 18.21 & 113.2 & 6.216 & 24.1 & 260 & 14.28 & 21.97 \\
\hline $\mathrm{Ba}$ & 6.049 & 13.87 & 2.293 & 71.9 & 250 & 41.33 & 57.86 \\
\hline Hf & 0.2676 & 2.974 & 11.116 & 42.7 & 3.0 & 11.21 & 11.21 \\
\hline $\mathrm{Zr}$ & 9.714 & 104.24 & 10.705 & 40.0 & 100 & 10.29 & 10.29 \\
\hline $\mathrm{Ta}$ & 0.0351 & 0.192 & 5.467 & 55.0 & $(1.0)$ & $(28.49)$ & - \\
\hline $\mathrm{Nb}$ & 0.6175 & 3.507 & 5.679 & 55.1 & 11.0 & 17.82 & 17.82 \\
\hline $\mathrm{U}$ & 0.0203 & 0.0711 & 3.496 & 52.3 & 0.91 & 44.76 & 61.49 \\
\hline $\mathrm{Th}$ & 0.0813 & 0.1871 & 2.300 & 69.3 & 3.5 & 43.04 & 59.03 \\
\hline $\mathrm{Pb}$ & 0.175 & 0.489 & 2.794 & 30.7 & 8.0 & 45.71 & 57.14 \\
\hline $\mathrm{Y}$ & 3.940 & 35.82 & 9.091 & 31.2 & 20.0 & 5.08 & 5.58 \\
\hline $\mathrm{Sc}$ & 14.88 & 41.37 & 2.784 & 9.8 & 30.0 & 2.02 & 2.02 \\
\hline Co & 104 & 47.07 & 0.453 & 7.9 & 29.0 & 0.279 & 0.24 \\
\hline $\mathrm{Ni}_{\mathrm{i}}$ & 2080 & 149.5 & 0.072 & & 105 & 0.050 & 0.014 \\
\hline $\mathrm{Cu}$ & 28.0 & 74.4 & 2.657 & 29.1 & 75 & 2.679 & 2.14 \\
\hline Sn & 0.150 & 1.382 & 9.213 & 32.4 & 2.5 & 16.67 & - \\
\hline
\end{tabular}

The data for the primitive mantle and N-MORB average are taken from Jochum et al. [4]. The N-MORB average represents 26 fresh MORB glasses, defined as N-type MORB by their light-REE depletion [5]. The values for the primitive mantle are taken from Hart and Zindler [6] for the major elements, and their factor of 2.51 is used to obtain the mantle values of the refractory trace elements from the abundances in $\mathrm{Cl}$ charbonacous chondrites. The sources of the $\mathrm{Cl}$ chondrite data are: $\mathrm{REE}$ [7], $\mathrm{Ba}, \mathrm{Sr}, \mathrm{Hf}$ [8], $\mathrm{Zr}, \mathrm{Ta}, \mathrm{Nb}$, $\mathrm{Y}, \mathrm{Sc}$ [9], $\mathrm{U}$ [10]. Other elements were obtained as follows: $\mathrm{Th}=4 \cdot \mathrm{U} ; \mathrm{Cu}, \mathrm{Ni}$, $\mathrm{Co}$ [11], $\mathrm{K}=12,700 \cdot \mathrm{U}[12], \mathrm{Rb}=\mathrm{Ba} / 12.3$ [13], $\mathrm{Cs}=\mathrm{Rb} / 20$ [14], $\mathrm{Sn}[15]$, and $\mathrm{Pb}$ from $\mu=8.88$ [1]. Most of these values are believed to be correct within about 10\%, except for Cs, for which different estimates differ by a factor of $4[13,14,16]$.

The data sources for the two continental crust averages are: TM1 [17, table 3.5, p. 67]; TM2 [17, table 3.3, p. 62] (this is the so-called andesite model).

All normalized values are derived by division of the concentration through the primitive mantle value. 


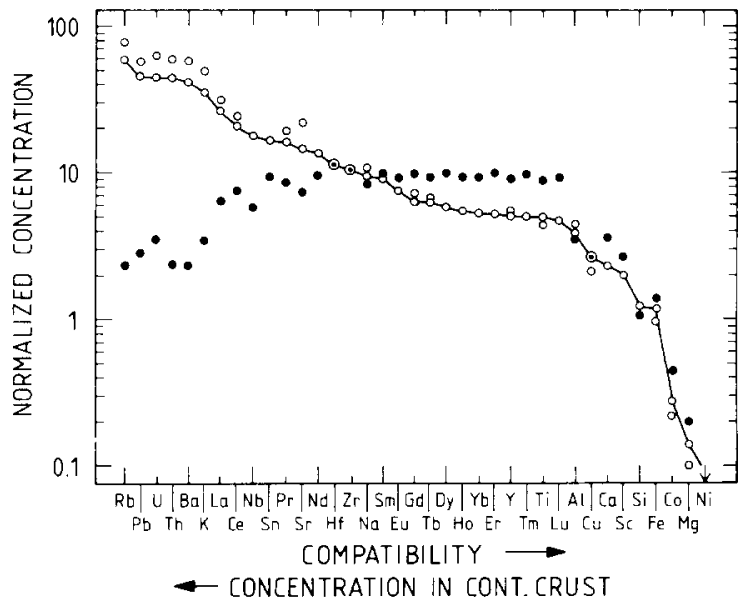

Fig. 1. Average compositions of continental crust (two estimates by Taylor and McLennan, [17], TM1 and TM2) and "normal-type" mid-ocean ridge basalts [4] from Table 1. All concentrations are normalized by division through the respective concentration of the primitive mantle (see also Table 1). The sequence of elements is determined by the order of decreasing concentrations in the continental crust average of Taylor and McLennan, TM1. These concentrations are connected by a solid line.

measure for the degree of element incompatibility in the mantle. The resulting sequence of elements is similar but not identical to the alternative sequence given in section 4.3 and to those used by other authors (e.g. $[5,19]$ ) to represent basalt compositions. The emerging patterns are strikingly simple. The monotonic decrease of the continental abundances is, of course, inherent in the design of the diagram. The highest abundances present are about 50 to 100 times those of the primitive mantle. Very few elements have enrichment factors less than unity. This is in part the result of the choice of elements: most siderophile elements have very low but poorly known abundances in crust and mantle (because they are concentrated in the core) and have been omitted from the diagram.

The overall MORB pattern is surprisingly regular, and most of the irregularities might well be the result of uncertainties in the composition of the average continental crust. In contrast with the continental pattern, the highest concentrations present are only about ten times primitive, and these are realized not by the most incompatible elements but by the moderately incompatible $\mathrm{Na}$, $\mathrm{Ti}, \mathrm{Y}, \mathrm{Zr}, \mathrm{Hf}$, and the intermediate to heavy REE. The regularity of the pattern suggests that the chemistry of MORB is related to the chemistry of the continental crust by some simple relationship between the mechanisms that govern the extraction of the continental crust and the production of MORB. More specifically, it will be shown below that most chemical elements have effective partition coefficients in the two processes that are either approximately the same or are at least related in some simple way.

The variabilities of the element concentrations expressed by the standard deviations (Fig. 2) are relatively low compared with other compilations of MORB data. This is the result of using a MORB population restricted to N-type trace element and isotopic abundances and to $\mathrm{MgO}$ concentrations of $5.6-9.0 \%(7.6 \pm 0.9 \%$ std. dev. $)$. These restrictions were applied in order to avoid strongly fractionated samples and basalts which might be derived from "anomalous" plume-type sources. The inherent circularity of these selection criteria is obvious but unavoidable. The population is therefore biased toward the most depleted end member of MORB. The relative chemical variations are still believed to be relevant for the purpose of this paper. If P-type MORB were to be included in the MORB data set, the highly incompatible element concentrations would be much more variable and their averages would become more uncertain, because of weighting uncertainties. However, the moderately incompatible elements would not be greatly affected.

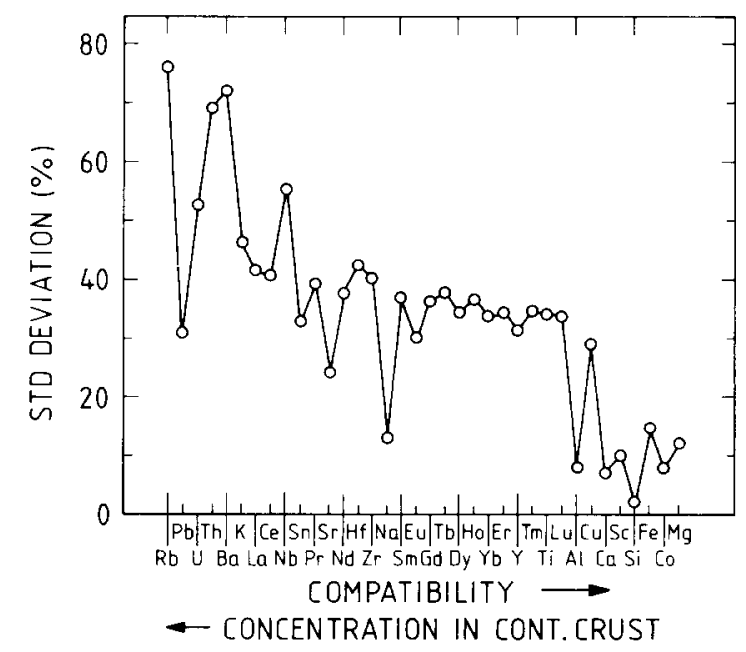

Fig. 2. Standard deviations of the average N-type MORB concentrations (from Table 1). The compatibility sequence is taken from Fig. 1. 
The important features of the MORB concentration pattern, which should be explained by any global differentiation model, are:

(1) The pattern has a distinct concentration maximum.

(2) The elements that define this maximum are the intermediate to heavy REE, Hf, $\mathrm{Zr}, \mathrm{Y}, \mathrm{Ti}$ and Na. These elements have experimentally determined bulk partition coefficients in the peridotite-basalt system ranging from 0.01 to 0.1 .

(3) The magnitude of the abundance maximum is about ten times the primitive-mantle values of these elements.

(4) The standard deviations of the average concentrations are small for major elements and increase systematically toward the left hand side of the diagram, as the elements become more incompatible. (A similar increase toward the right, affecting mostly $\mathrm{Ni}$ and $\mathrm{Cr}$, is known to be caused by variable fractionation of olivine and chromite in the basalts and is not further considered here.)

\section{Extraction model}

The crust-mantle differentiation is approximated by the following two-stage model:

Stage 1: A partial melt (possibly including an aqueous fluid), is extracted from the mantle to form the continental crust. The residual mantle is concurrently or subsequently rehomogenized and forms the depleted mantle reservoir.

Stage 2: After some (unspecified) period of time lasting perhaps 1-2 $\mathrm{Ga}$, the residual (depleted) mantle reservoir is remelted and generates MORB.

The "residual mantle" is not necessarily the entire mantle but only that portion which participates in the differentiation process. Both partial melting events are modeled as simple equilibrium melting. The normalized concentration of an element in the partial melt of stage 1 is:

$C_{1}^{*}=\frac{c_{1}}{c_{0}}=\frac{1}{D_{1}+F_{1}\left(1-D_{1}\right)}$

The concentration in the solid residue is:

$$
C_{\text {res }}^{*}=D_{1} C_{1}^{*}
$$

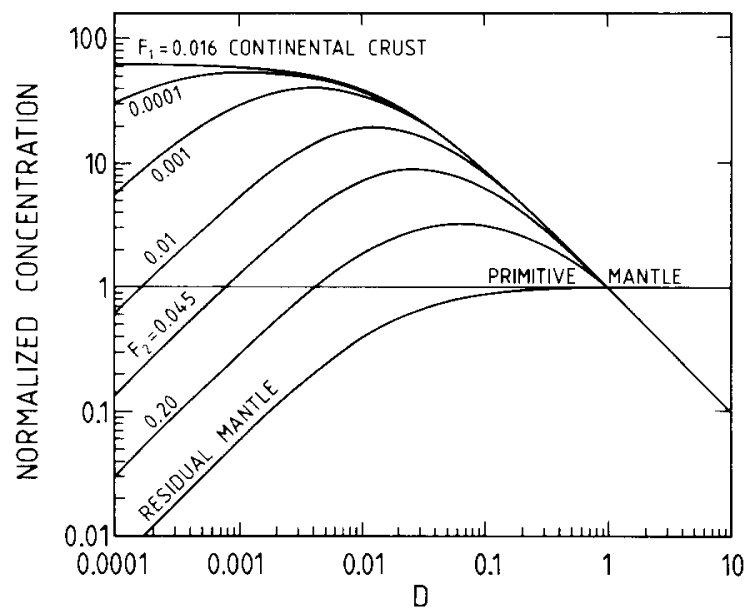

Fig. 3. Normalized concentrations of arbitrary chemical elements as a function of bulk partition coefficient. The curve labeled $F_{1}=0.016$ represents a partial melt of the primitive mantle. The curve labeled "residual mantle" represents the residue from the $F_{1}$ partial melt, and the remaining curves labeled $F_{2}=0.2$ to $F_{2}=0.0001$ represent partial melts of this residue. These have been calculated from equations (1), (2), and (3), assuming that the bulk partition coefficients $D_{1}=D_{2}$ for all elements. Stage 1 simulates a partial melt with the composition of the continental crust, and its melt fraction is chosen to match approximately the maximum normalized concentration found in average continental crust. The second-stage melt that matches the concentration maximum of MORB $(=9$ to 10 times primitive mantle) is obtained for a melt fraction of $F_{2}=0.045$

so that the concentration in the partial melt of stage 2 is:

$C_{2}^{*}=\frac{c_{2}}{c_{0}}=\frac{D_{1}}{\left[D_{1}+F_{1}\left(1-D_{1}\right)\right]\left[D_{2}+F_{2}\left(1-D_{2}\right]\right.}$

where $c$ is the concentration of an element in the melt, $c_{0}$ is the concentration in the primitive mantle, $C^{*}$ is the normalized concentration in the melt, $D$ is the bulk partition coefficient of the element ( $\left.D=c_{\text {solid }} / c_{\text {melt }}\right)$, and $F$ is the melt fraction. The subscripts 1 and 2 refer to stages 1 and 2 of the model.

Fig. 3 shows $C_{1}^{*}$ and $C_{2}^{*}$ as functions of $D$ for the case where $D_{1}=D_{2}, F_{1}=0.016$ and a series of $F_{2}$ values ranging from 0.0001 to $0.2 . F_{1}$ has been chosen so that the maximum abundances of the continental crust in Fig. 1 are matched by the calculated curve for $C_{1}^{*} . F_{1}$ is well constrained to the extent that the concentrations of highly incompatible elements in the bulk continental crust are 
known. The MORB abundance maximum of Fig. 1 is matched by the curve for $F_{2}=0.045$. This melt fraction is more model dependent, and it will be seen later that the best estimate for the effective MORB-melt fraction is approximately $F_{2}=0.10$. The point of the present, oversimplified approach is to illustrate how the fundamental differences between the chemistries of the continental and oceanic crusts can be explained by a very simple two-stage process. In stage 1 , the most highly incompatible elements are most strongly enriched relative to the starting material, the primitive mantle. The magnitude of that enrichment factor is $C_{1}^{*} \approx 1 / F_{1}$, as long as these elements are sufficiently incompatible so that $D_{1} \ll F_{1}$. This causes a depletion in the residual mantle which will be reflected by the composition of any subsequently produced melt. In stage 2 , and in any conceivable additional stages, the maximum concentration relative to the original mantle shifts to more compatible elements. It is formed by those elements with intermediate partition coefficients, which incorporate the optimum combination of least depletion during stage 1 and highest enrichment during stage 2.

The existence of a normalized-concentration maximum in MORB defined by elements of intermediate partition coefficients has not been widely appreciated, because in conventional representations of MORB chemistry using normalized concentrations (sometimes called spidergrams, a term that is misleading at best), the major elements and the compatible trace elements are omitted. When the more nearly complete lithophile element chemistry is displayed, and an adequate measure for the relative partition coefficients is used, it becomes obvious that the MORB concentrations decrease toward the left-hand side of the curve because the MORB source is depleted in these elements, and the concentrations also decrease toward the righthand side because they are progressively more strongly retained in the mantle. Moreover, the solid residue after stage 1 is virtually unchanged from the original primitive mantle composition on the right-hand side of the MORB maximum.

It is easy to verify that different assumptions about the exact nature of the melting process (e.g. fractional melting), the magnitude of the melt fractions, the introduction of additional stages of melt extraction, and the modification of the melt chemistry by fractional crystallization will change the position and the magnitude of the concentration maximum, but the final concentration curves will be qualitatively similar to the hypothetical MORB curves in Fig. 3 and to the real MORB curve in Fig. 1. Fig. 3 shows that, as the melt fraction $F_{2}$ decreases, the concentration maximum increases in magnitude and shifts to elements with lower bulk partition coefficients. In this idealized model, the highest concentration that can be attained by such a stage- 2 melt is the same as the maximum attained during stage 1 . This maximum is approached as $F_{2}$ approaches zero. This means in general that the residual mantle is incapable of producing second-stage melts with element concentrations exceeding the maximum concentrations found in the continental crust, unless there is another enrichment process, which either pre-enriches the source or "post-enriches" the melt (for example by crystal fractionation). It seems likely that the very high trace element enrichments found in many alkali basalts of oceanic islands require such a pre-enrichment.

\subsection{Refinements of the model}

Retention of melt or reinjection of continental crust during stage 1 . The concentrations of $\mathrm{Rb}, \mathrm{Ba}, \mathrm{Th}$ and $\mathrm{Pb}$ in MORB on the left-hand side of Fig. 1 show an apparent levelling off slightly above primitive-mantle values. (Cs must be disregarded because its primitive-mantle abundance is poorly known; see discussions in $[13,14,16]$.) Conceivably, this may be so because all these elements have similar bulk partition coefficients. More likely, they have very low, but different partition coefficients and the levelling off is caused by retention of small amounts of melt in the mantle or by reinjection of crust.

The abundances in the second-stage melt are then described by the equation:

$$
\begin{aligned}
C_{2}^{*}= & \left\{D_{1}+F_{1}\left(1-D_{1}\right)-F_{1}(1-\alpha)\right\} \\
& \times\left\{\left[D_{1}+F_{1}\left(1-D_{1}\right)\right]\left[D_{2}+F_{2}\left(1-D_{2}\right)\right]\right. \\
& \left.\times\left[1-F_{1}(1-\alpha)\right]\right\}^{-1}
\end{aligned}
$$

where $\alpha$ is the fraction of the first-stage melt remaining or reinjected into the residue. Fig. 4 shows an example of a second-stage melt for a value of $\alpha=0.1$. An important point to note is 


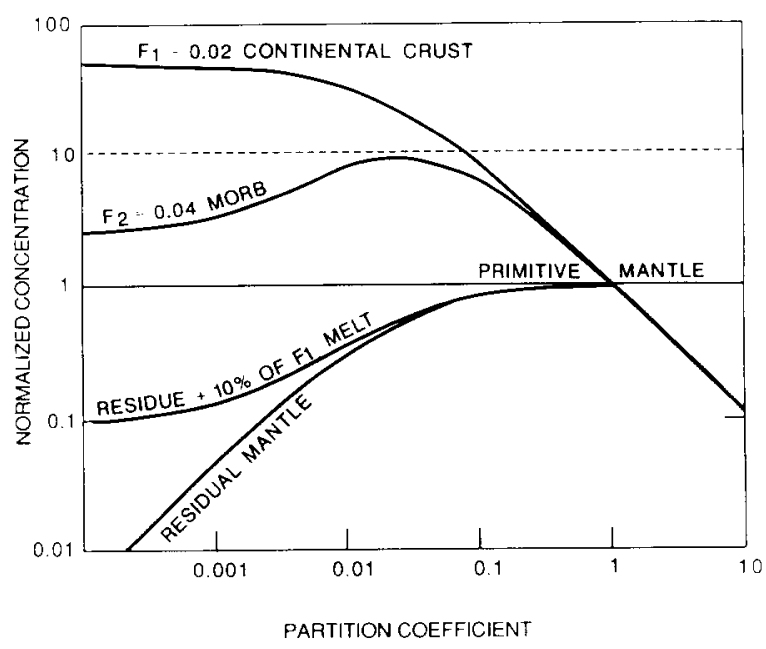

Fig. 4. Effect of retention of a portion of stage-1 melt on the concentrations in the residue and in a stage- 2 melt, calculated from equation (4) and $\alpha=0.1$.

that the abundance maximum is not sensitive to the value of $\alpha$, as long as $\alpha<0.1$.

$A$ quantitative model for the composition of MORB. In the simple model discussed so far, it has been assumed that the bulk partition coefficient is the same for each element during stages 1 and 2, respectively. This assumption is unrealistic because it would require not only identical mineral compositions and melting conditions for both processes but also identical melt fractions. Actually, the coefficient $D$ in equation (1) varies as a function of the melt fraction $F$, because the relative proportions of the residual minerals change as a function of melt fraction (except for the special but unrealistic case of so-called modal melting).

A better approximation to melting with constant coefficients may be modeled with the equation of Shaw [20]:

$C_{1}^{*}=\frac{c_{1}}{c_{0}}=\frac{1}{D_{1}^{0}+F(1-P)}$

where $D^{0}$ is the bulk partition coefficient of the element in question in the unmelted source rock (i.e. the sum of the individual mineral/melt coefficients weighted in the proportions of the minerals in the initial source rock), and $P$ is the bulk partition coefficient "of the melt" (i.e. the bulk mineral/melt coefficient weighted in the proportions in which the minerals are consumed by the melt). $P$ will be approximately constant and independent of the melt fraction as long as the melt has an approximately invariant major element composition.

If the mineralogy of the residual solid phases is different during stages 1 and 2 , the assumption that $D^{0}$ and $P$ remain the same is still not justified. For example, if continental crust originates during subduction processes and at a depth sufficient for garnet to be stable during the generation of the melts, the bulk partition coefficients for the heavy REE will be much greater during stage 1 than during stage 2 when MORB is generated at pressures below the stability field of garnet.

In order to convert the qualitative abscissa of Fig. 1 to a scale of quantitative bulk partition coefficients, each element will be assigned a value of $D_{1}$ which is calculated as follows: $F_{1}$ is estimated from the concentration of the most incompatible element in the continental crust, assuming that this element has a bulk partition coefficient $D_{1}=0$, so that equation (1) reduces to $C_{1}^{*}=1 / F_{1}$. Once the value of $F_{1}$ has been fixed, the residual concentrations of all other elements may be calculated from their respective concentrations $C_{1}^{*}$, using an alternative to equation (2), which may be derived directly from the mass balance between melt and residue, namely:

$C_{\text {res }}^{*}=\frac{1-C_{1}^{*} F_{1}}{1-F_{1}}$

Equations (2) and (6) may then be combined to obtain the bulk partition coefficient of any element:

$D_{1}=\frac{C_{\mathrm{res}}^{*}}{C_{1}^{*}}=\frac{1-C_{1}^{*} F_{1}}{\left(1-F_{1}\right) C_{1}^{*}}$

In this way, an effective bulk partition coefficient is obtained for each element from its concentration in the continental crust. The qualitative values on the abscissa of Fig. 1 have been quantified in this manner and plotted in Fig. 5.

Equation (5) has been applied to stage 2 as follows: The value of $P_{2}$ is assumed to be higher than $D^{0}$ by a factor of four for all incompatible elements with bulk partition coefficients $D^{0} \leqslant 0.5$. This assumption takes account of the well-known fact that essentially all the incompatible elements shown in Fig. 1, including the major elements $\mathrm{Al}$ and $\mathrm{Ca}$, have much higher partition coefficients in 


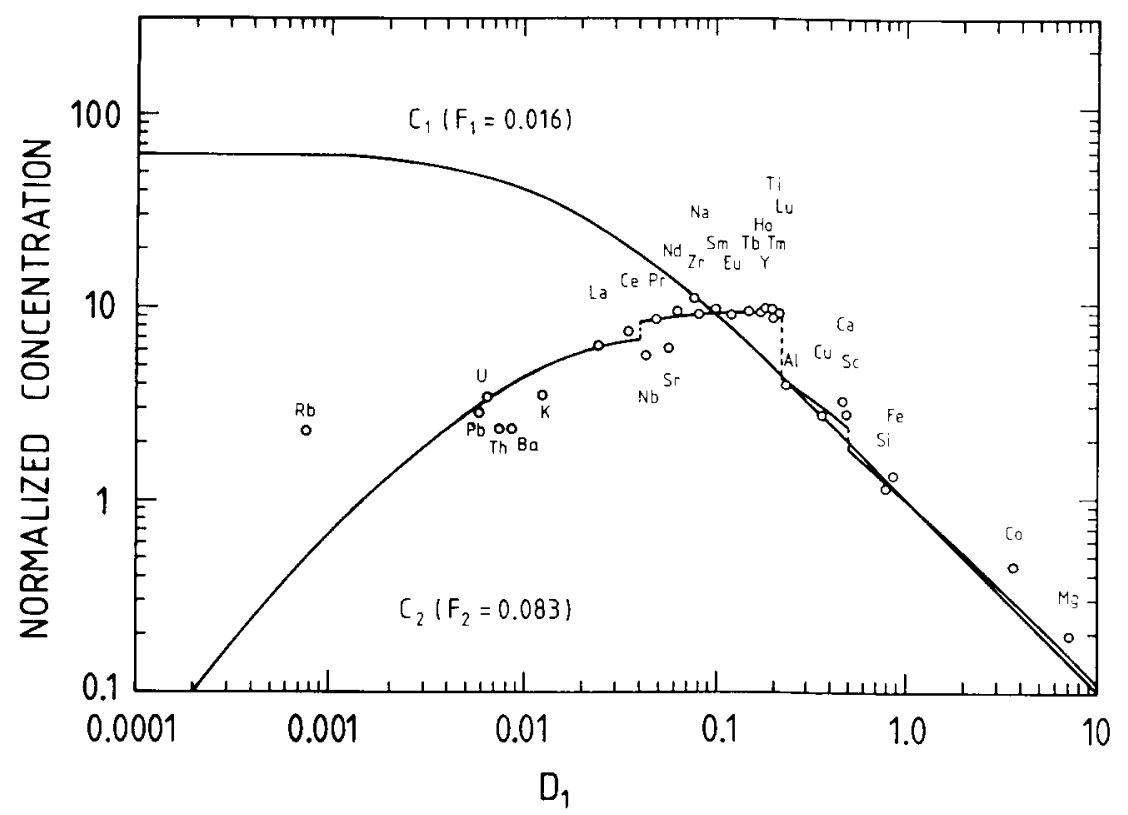

Fig. 5. Concentration versus bulk partition coefficient $D_{1}$ of a stage-1 melt as in Fig. 3. The stage-2 melt is calculated from equation (5) with the assumptions that $D_{2}^{0}=0.2 D_{1}$ for all $0.05<D_{1}<0.22$, and $P_{2}=4 D_{2}^{0}$ for all $D_{2}^{0}<0.5$. The labeled points are the normalized MORB-average concentrations from Table 1 . The $D_{1}$ value of each element has been calculated from equation (7) with $F_{1}=0.016$ and $C_{1}=$ continental crust average TM1.

clinopyroxene and in garnet than in olivine and orthopyroxene. Clinopyroxene and garnet constitute only $15-20 \%$ of the mantle mineral assemblage, but they are preferentially consumed by any melt being formed. Therefore, the value of $D^{0}$ is dominated by olivine and orthopyroxene, but $P$ is dominated by clinopyroxene and, if stable, garnet. In addition, it is assumed that $D_{2}^{0}=0.2 D_{1}$, for all $0.05<D_{1}<0.22$. This apparently arbitrary choice is intended to account for the differences caused by the possible presence of garnet during stage 1 and its absence during stage 2 . Garnet has a very strong effect on the bulk partition coefficients of the middle and heavy REE. It is much less important for the light REE and other highly incompatible elements. Its effect on $\mathrm{Ca}$ and $\mathrm{Al}$ partitioning is also much smaller than on the heavy REE.

Fig. 5 shows a concentration curve for MORB, modified by the above assumptions, which is overall similar to that of the simple model used in Fig. 3 . However, the melt fraction for the generation of MORB is now almost twice as high $\left(F_{2}=0.083\right)$ as in the simplest model $\left(F_{2}=0.045\right)$, and the concentrations of the elements corresponding to $D_{1}=$
0.1 to 0.22 , which correspond to the middle and heavy REE, are higher than the respective concentrations in the continental crust.

The MORB data from Table 1 are plotted in Fig. 5 for comparison with the calculated MORB curve. The corresponding continental concentrations are not specifically shown. They lie exactly on the $C_{1}^{*}$ curve because equation (7) automatically yields an exact fit to that curve.

For the major and the moderately incompatible elements, the fit of the MORB data in Fig. 5 is surprisingly tight. The scatter is greater for the highly incompatible elements, but this is expected because of their intrinsically greater variability, the uncertainties of the partition coefficients, and the fact that other effects such as retention of melt during stage 1 or fractional crystallization during stage 2 have all been neglected.

The range of $D$ values that correspond to the MORB abundance maximum is $D_{1}=0.05-0.2$, and $D_{2}^{0}=0.01-0.04$. This may be compared with experimental data as a check for the internal consistency of the model. Of particular importance are the partition coefficients of the heavy REE, because these elements have the highest 
concentrations in MORB relative to the continental crust. This overlap requires relatively high partition coefficients during stage 1 . Green and Pearson [21] have recently summarized their own new experimental data on clinopyroxene partitioning as well as other data from the literature. They recommend $D_{\mathrm{Ho}}$ values ranging from 0.3 to 1.1 for mantle melting depending on temperature and $\mathrm{SiO}_{2}$ content of the melt. Thus a residual mantle assemblage containing 10\% clinopyroxene and no other REE-bearing minerals would have a bulk partition coefficient between 0.03 and 0.1 . These values would be further increased if a small amount of residual garnet were present in the residue of stage 1 . During stage 2, no garnet would be present, $\mathrm{SiO}_{2}$ contents in the melt would be low, and temperatures would be high relative to stage 1 . These differences would cause the clinopyroxene partition coefficient to be relatively low, on the order of $0.2-0.3$, and this would lower their bulk partition coefficient to about $0.02-0.03$. These considerations show that the bulk partition coefficients estimated from experimental data are indeed consistent with the model illustrated in Fig. 5 and the actual geochemical data. This agreement lends support to the general validity of the model in spite of its extreme simplicity.

\subsection{Constraints on melt fraction during MORB} production

It has just been shown that a relatively minor refinement in the melting model applied to stage 2 yields a substantially higher melt fraction than the simplest model described by equation (3). It is therefore appropriate to ask whether the melt fraction of MORB can be constrained at all. An upper limit for $F_{2}$ is indeed found, if one assumes that the partition coefficients, $D_{2}$, of the elements that define the MORB concentration maximum are equal to zero. In this case, equation (3) is reduced to $C_{2}^{*}=C_{\mathrm{res}}^{*} / F_{2}$, and this may be rearranged and evaluated using equation (6) to yield:

$F_{2}=\frac{1-C_{1}^{*} F_{1}}{\left(1-F_{1}\right) C_{2}^{*}}$

The most restrictive case will be given by the element which combines the highest value of $C_{1}^{*}$ with the highest value of $C_{2}^{*}$. This element is $\mathrm{Zr}$ which has values of $C_{1}^{*}=10.4$ and $C_{2}^{*}=10.9$ and yields $F_{2}=0.078$. This is actually lower than the value of $F_{2}=0.083$ found for the model shown in Fig. 5. The reason for this is that $C_{2}{ }^{*}$ of zirconium is exceptionally high, and a maximum value of $C_{2}^{*}=9$ has been used in Fig. 5. Other elements near the MORB maximum, $\mathrm{Y}, \mathrm{Ti}, \mathrm{Na}$ and the REE, yield maximum melt fractions between 8.3 and $10.8 \%$. This means that a melt fraction of $F_{2} \simeq 10 \%$ is a rather firm upper limit, provided that the concentrations of these elements in MORB have not been raised significantly by fractional crystallization. The problem of fractional crystallization will be addressed further below.

If the two-stage melting model is replaced by multiple stages, the final melt fractions must become smaller, if the same abundance maximum is to be maintained in the final MORB production stage. If we relax the constraint that the depletion is produced by previous production of the continental crust, and retain only the constraint of the maximum enrichment factor $C_{2}^{*}=9$ in MORB, the upper limit for the melt fraction producing MORB is still only $F_{2}=0.11$. This is a direct consequence of equation (1). Slightly larger melt fractions are obtained for more efficient extraction mechanisms such as fractional melting and the continuous extraction discussed by Ribe [22]. These more detailed considerations are beyond the scope of this paper.

\subsection{Comparison with the melt fractions inferred by Klein and Langmuir}

Klein and Langmuir [1] have presented a new and comprehensive interpretation of the major element chemistry of MORB. They showed that the positive correlation of $\mathrm{Na}_{2} \mathrm{O}$ and the negative correlation of $\mathrm{FeO}$ and $\mathrm{CaO} / \mathrm{Al}_{2} \mathrm{O}_{3}$ with axial depth can be explained by temperature differencer in the mantle, which control the depth of initial melting, the aggregate melt fraction, the thickness of the resulting oceanic crust, and its depth below sea level. They estimated melt fractions of $8-20 \%$ from the total range of $\mathrm{Na}_{2} \mathrm{O}$ contents ranging from 1.7 to $3.4 \%$ in MORB, and mantle concentrations of 0.30 ( $=$ primitive mantle) and 0.26 (= depleted mantle). They also indicated that these melt fractions represent maximum estimates. For the average MORB composition corresponding to an axial depth of $3000 \mathrm{~m}$, Klein and Langmuir obtained an aggregate melt fraction of $10 \%$. 
In the context of the present paper, the concentration of the depleted mantle is constrained by the previous extraction of the continental crust, which has a normalized concentration of $C_{\mathrm{Na}}^{*}=$ 9.34 in Taylor and McLennan's [17] most recent estimate, of 10.54 in their earlier "andesite model". These correspond to normalized $\mathrm{Na}$ concentrations for the depleted mantle (using equation (6) with a value of $F_{1}=0.016$ ) of 0.864 and 0.845 , respectively, which correspond to absolute $\mathrm{Na}_{2} \mathrm{O}$ concentrations of 0.259 and $0.253 \%$, respectively (using a primitive mantle value of $\mathrm{Na}_{2} \mathrm{O}=0.30$ [1]). These $\mathrm{Na}$ contents of the depleted mantle are only slightly lower than $\mathrm{Na}_{2} \mathrm{O}=0.26$ used by Klein and Langmuir. Equation (5), using $D_{2}^{0}(\mathrm{Na})$ $=0.03, \quad P_{2}(\mathrm{Na})=0.11$ (following [1]), and $C_{2}^{*}$ $(\mathrm{Na})=7.61$ (the fractionation corrected mean MORB value $)$ yields $F_{2}=\left(C_{\text {res }}^{*} / C_{2}^{*}-D_{2}^{0}\right) /(1-$ $\left.P_{2}\right)=0.094$ and 0.091 , respectively. These results are near the lower end of the range of $8-20 \%$ given by Klein and Langmuir. Overall, there is no serious disagreement, because Klein and Langmuir estimated a melt fraction of 0.10 for the MORB composition which corresponds to the best present estimate of a representative mean value for all MORB.

The general conclusion derived from the above arguments is that the only way in which the overall, aggregate melt fraction of average MORB can be made to be greater than $9-11 \%$ (derived in this and the previous section) is to call for a mechanism other than melting to increase the concentrations of trace elements in MORB. The most popular of these is crystal fractionation in a crustal magma chamber. Although a full discussion of this subject is beyond the scope of this paper, the following brief evaluation is in order.

\subsection{Trace element enrichment of MORB through fractional crystallization}

Whether fractional crystallization is quantitatively important for the absolute concentrations of trace elements in the final melt depends to a large extent on the major element composition of the primary melt that crosses the mantle-crust boundary. (Early fractionation of melts within the mantle may also occur but is not relevant in the present context.) If the primary melt is a basalt, then fractional crystallization will cause only a relatively minor enrichment of incompatible ele- ments in the average final basalt, because this average still has a relatively "primitive" composition. On the other hand, if the primary melt is a highly magnesian picrite or komatiite, the amount of fractional crystallization needed to produce the final basalt is much larger and the degree of incompatible-element enrichment is greater.

For the sake of argument, two "worst-case" scenarios will be assumed. The first is a picritic primary melt containing $18 \% \mathrm{MgO}$. This magma undergoes closed-system crystal fractionation which is dominated by olivine crystallization. By the time this magma has crystallized enough olivine to lower the $\mathrm{MgO}$ concentration to the value of $8 \%$, the concentrations of the olivine-incompatible elements have increased by only $35 \%$.

Alternatively, the trace element enrichment may be effected by the crystallization processes in a so-called RTF ("replenished, tapped, fractionated") open-system, steady-state magma chamber $[23,24]$. In principle, this process may enrich the incompatible elements in the magma by an arbitrarily large factor, which depends primarily on the ratio of crystallized solids to erupted melt. There are, however, several compelling reasons to conclude that in ordinary MORB this mechanism is not very efficient. A full treatment of this subject will be presented elsewhere. Here, I mention only three of the reasons:

(1) MORB are distinguished by depletion, not enrichment, of incompatible elements. For example, the ratio of $\mathrm{Rb}$ to $\mathrm{Sr}$ in MORB is $\mathrm{Rb} / \mathrm{Sr}=$ 0.011 , which is almost a factor of three lower than $\mathrm{Rb} / \mathrm{Sr}=0.029$ of the primitive mantle:

(2) RTF processes involving gabbroic crystal fractionation would change all concentration ratios of elements affected by feldspar crystallization. This includes $\mathrm{Eu} / \mathrm{Eu}^{*}$ and $(\mathrm{Na} / \mathrm{Zr})_{\mathrm{N}}$, which average 0.95 and 0.74 , respectively, but should decrease significantly in response to feldspar crystallization.

(3) Extensive and variable RTF processes would destroy the relationship between axial depth and chemistry [1].

Overall, the enrichment factor affecting the concentrations of incompatible elements in the erupted liquid relative to the primary melt entering the oceanic crust is probably on the order of 1.5 or less for average MORB.

Fractional crystallization is one of the ways in 


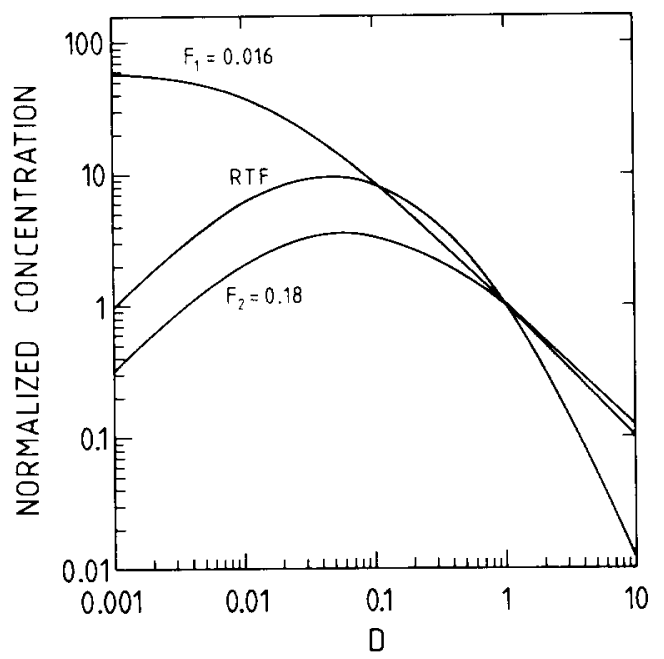

Fig. 6. Concentration curves for a stage- 1 melt $\left(F_{1}=0.16\right.$ as in Fig. 3), a primary stage-2 melt with a melt fraction $F_{2}=0.18$, and a fractionated stage- 2 melt labeled "RTF". The fractionation model used is that of O'Hara [23] for a steady-state magma chamber which is periodically refilled, tapped and fractionated. The ratio of the amounts of crystal cumulate to liquid tapped from the chamber is $X / Y=2$. The steady-state fractionated melt shows a concentration curve which overlaps the stage-1 melt at $D$ values between 0.1 and 0.5 . This is in qualitative agreement with the relationship found in Fig. 1. However, for values of $D>1$, the RTF melt has much lower concentrations than the $F_{1}$ melt. For a bulk partition coefficient of $D=10$, the difference is almost a factor of ten.

which the crossover of the concentration curves in Fig. 1 might be produced. (A significant decrease in partition coefficients during stage 2 was another way discussed earlier.) Fig. 6 shows an example of this. A relatively high melt fraction of $F_{2}=0.18$ has been used, and the concentrations of the incompatible elements have been increased by assuming an RTF model with the parameter $X=0.1$ ( $=$ fraction crystallized in each fractionation cycle) and $Y=0.05$ ( $=$ fraction erupted in each cycle; see $[23,24])$. This increases the concentrations of the most highly incompatible elements by a factor of three (i.e. much higher than inferred from the small negative $\mathrm{Eu}$ anomaly actually found in average MORB). This purposely exaggerated example illustrates how fractional crystallization can, in principle, cause the observed crossover of MORB and continental abundances.

\section{Other properties of MORB}

\subsection{Retention of $\mathrm{Ca}, \mathrm{Al}$ and $\mathrm{Sc}$ in the MORB source}

These elements constitute a portion of the right-hand descending limb of the MORB abundance curve (Fig. 1), and their abundances are substantially lower than the maximum of that curve. Consequently, they are sufficiently compatible to be partly retained in the mantle by the residue of MORB. Of the major minerals in the mantle (olivine, orthopyroxene, clinopyroxene, garnet and spinel), only aluminous clinopyroxene is capable of retaining sufficient concentrations of all three of these elements. Clinopyroxene has a partition coefficient for $\mathrm{Sc}$ ranging from about 1 to 3 [25], depending on temperature, and it appears that it is the only phase capable of buffering the $\mathrm{Sc}$ abundances in MORB at the observed value of about $41 \pm 4 \mathrm{ppm}$. If this is correct, then the degree of MORB melting must normally be low enough so that clinopyroxene survives in the residue, and this residue cannot be a severely depleted harzburgite consisting only of olivine and orthopyroxene. Buffering of $\mathrm{Ca}$ by residual clinopyroxene has also been confirmed by observations in oceanic peridotites $[26,27]$.

Sun and Nesbitt [28] and Sun et al. [5] have used the same reasoning to show that in some MORB samples in the $\mathrm{Al} / \mathrm{Ti}$ and $\mathrm{Ca} / \mathrm{Ti}$ ratios do approach primitive-mantle values. In these cases the degree of melting is indeed high enough so that clinopyroxene has been consumed by the melt. The lower $\mathrm{Al} / \mathrm{Ti}$ and $\mathrm{Ca} / \mathrm{Ti}$ ratios of average MORB, on the other hand, show that such high degrees of melting are the exception rather than the rule.

The retention of $\mathrm{Sc}, \mathrm{Al}$ and $\mathrm{Ca}$ in the mantle is probably the strongest evidence in favor of degrees of melting that are low enough for clinopyroxene to survive in the residue. This result is in apparent disagreement with most conventional petrological thinking about the oceanic crust and specifically with the inferences drawn from the ophiolite model of the oceanic crust. One of the reasons for inferring high degrees of melting has been the common occurrence of highly depleted harzburgites beneath the cumulate gabbroic sections in ophiolites. I believe that this observation is misleading, because the harzburgites represent only the upper- 
most portion of the residual mantle, which is not representative of the entire mantle column from which partial melts are extracted. The melt fraction in this column is smaller at its base than at its top. Therefore, observations on residual peridotites are biased toward the top of the column, where melt fractions are largest. Observations on incompatible element concentrations and ratios are biased toward the lower part of the column, where melt fractions are smaller. Overall, the batch melting model can only be used as a very rough approximation to the actual melt extraction.

Another reason for the disagreements lies in the differences in sampling philosophies. Most authors (e.g. [5,28]) believe that the basalts richest in $\mathrm{MgO}$, or highest in $\mathrm{Mg} / \mathrm{Fe}$, represent the most "primitive" melts and are therefore also the best representatives of the parental liquids of the more evolved, less magnesian basalts. I believe that this approach automatically introduces a serious sampling bias toward basalts derived from high primary melt fractions. Bryan et al. [29] have shown that the more common, "garden variety" of MORB, which contain about $7-8 \% \mathrm{MgO}$, are not derived from these more magnesian melts but stem from different parent liquids. Klein and Langmuir [1] demonstrated that melt fractions vary by more than a factor of two along the global ridge system. If one selects only the basalts highest in $\mathrm{MgO}$, which are most likely to be derived from the highest melt fractions, basalts derived from lower melt fractions will be systematically excluded. By avoiding the bias toward high melt fractions, one must accept another: the "garden variety" MORB have almost certainly evolved to some degree by fractional crystallization. However, for a given change in $\mathrm{MgO}$ concentration, the effect of fractional crystallization on the incompatible element concentrations in the melt is much smaller than the effect of differences in the primary melt fraction (see also section 3.4 ).

\subsection{Variation of the element abundances in $M O R B$}

The standard deviation of the MORB data is used as a measure for the real variability of the element abundances. This approach must be questioned because the sample selection has been biased in favor of the more depleted, so-called $\mathrm{N}$-type MORB in order to avoid plume type basalts which may be derived from qualitatively different source reservoirs. This sample bias causes a large reduction in the variations of the highly incompatible elements, because these elements are strongly enriched in plume-type basalts. Nevertheless, the standard deviations of the MORB population thus restricted still show a strong correlation with the degree of incompatibility (Fig. 2).

The observed variability may be ascribed to three causes: variable fractional crystallization, variable degrees of partial melting, and variable source depletion. The effects of these three processes on the concentration of a given element depend strongly on the bulk partition coefficient of that element. The degree of source depletion is likely to be nearly constant for the moderately incompatible elements that form the right-hand portion of the concentration maximum in MORB, because the depletion of these elements in the residual mantle is small. For example, the depletion factor for $\mathrm{Na}$ was calculated in the previous section to be about 0.85 for a stage- 1 melt fraction of $F_{1}=0.016$. Changing $F_{1}$ by a factor of two causes a change in $C_{\text {res }}^{*}$ of only $10 \%$. It is therefore a reasonable approximation to treat the source concentrations of this element as constant and to ascribe the differences in the observed, fractionation-corrected $\mathrm{Na}_{2} \mathrm{O}$ concentrations to differences in melt fraction. The (corrected) $\mathrm{Na}_{2} \mathrm{O}$ concentrations summarized in Table 1 range from 1.62 to $3.32 \%$ with a standard deviation of $15 \%$ of the mean. The melt fractions calculated from equation (5) range from 6 to $16 \%$ with a mean of $9.7 \%$ and a standard deviation of $26 \%$.

This range of melt fractions will affect the concentrations of the highly incompatible elements more severely than the $\mathrm{Na}$ concentration, because $C=C_{0} / F$ as $D$ approaches zero. In addition, the more highly incompatible elements are probably more heterogeneous in the MORB source, because changes in stage- 1 melt fractions will be more directly translated into changes in the residual concentration. For example, for elements with bulk partition coefficients of $D=0.01$, the residual concentration changes by a factor of two if the $F_{1}$ melt fraction changes by a factor of three.

These considerations lead to the expectation that the bulk partition coefficients of the elements should be negatively correlated with the standard 
deviations of the concentrations in MORB, and this is indeed observed in Fig. 2. The most noticeable exceptions in this general trend are the anomalously low standard deviations of the $\mathrm{Pb}$, $\mathrm{Sr}$, and $\mathrm{Na}$ concentrations. Part of this effect is caused by variable fractionational crystallization involving plagioclase, which will cause the REE and other incompatible element concentrations to vary, while at the same time buffering $\mathrm{Na}, \mathrm{Sr}$, and possibly also $\mathrm{Pb}$ because of its high partition coefficient for these elements. In addition, it will be shown below that the compatibility sequence used in Fig. 2 is inappropriate for $\mathrm{Pb}$ in MORB, where its actual, effective partition coefficient is closer to that of $\mathrm{Ce}$.

\subsection{Alternative compatibility sequence based on} oceanic basalts

Up to this point, the compatibility sequence of the elements (which is taken to be synonymous with the order of their bulk partition coefficients between solid and melt) has been based exclusively on the relative element concentrations in the

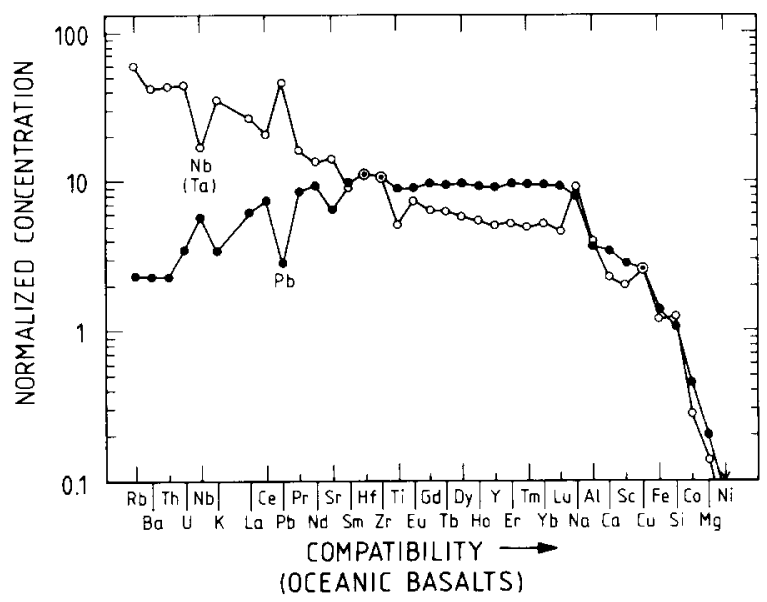

Fig. 7. Normalized element concentrations of average continental crust TM1 and average MORB (Table 1). The sequence of elements corresponds to the order of compatibility determined by Jochum et al. [4] on the basis of element ratio to element concentration correlations in oceanic basalts. The sequence is similar to that based on continental average concentrations (Fig. 1), but $\mathrm{Nb}, \mathrm{Ta}$, and $\mathrm{Pb}$ are significant exceptions. The "negative anomalies" of $\mathrm{Nb}$ and $\mathrm{Ta}$ in continental crust and island arc volcanics commonly discussed in the literature are based on approximately this kind of plot rather than Fig. 1. The even larger $\mathrm{Pb}$ anomaly is not found in the literature, because $\mathrm{Pb}$ is erroneously assumed to be highly incompatible in MORB because of its low concentration.

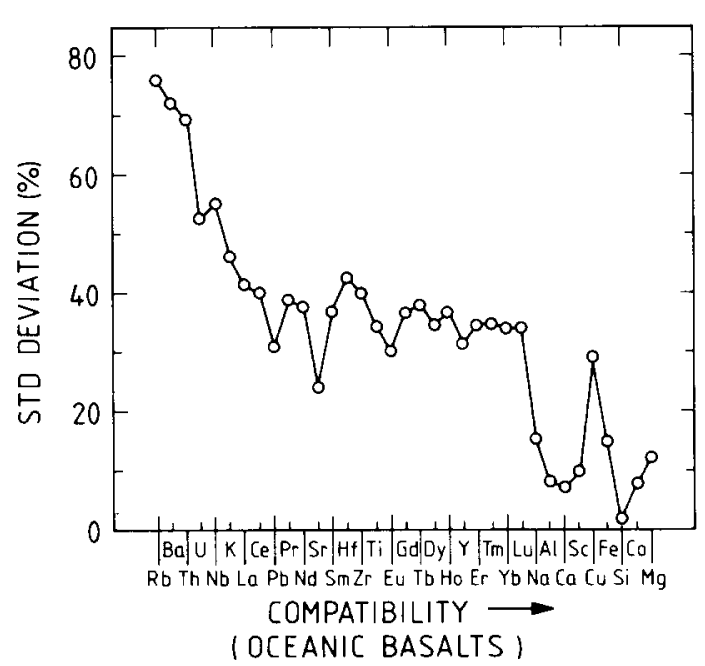

Fig. 8. Standard deviation versus compatibility for the compatibility sequence used in Fig. 7.

continental crust. This approach implied that the bulk partition coefficient of each element is identical (or at least similar) during the first (continental) and the second (oceanic) stages of melt extraction, respectively. This assumption is supported by the regularity of the element concentration pattern in average MORB (Fig. 1). Nevertheless, the anomalies in the standard deviations of the MORB sequence shown in Fig. 2, and discussed above, point to possible inconsistencies for some elements.

An alternative compatibility sequence has been derived which is based directly on the chemistry of oceanic basalts and is independent of the continental crust [4]. The method for this uses the slope of the concentration ratio of two elements versus the concentration of one of the elements. If the slope is zero, then both elements are equally incompatible [2]. If the slope is greater than zero, the element in the numerator is more incompatible. We have systematically examined our set of MORB and OIB data in this manner and have thus derived a basalt-based compatibility sequence [4]. Fig. 7 shows the average continental crust and MORB concentrations plotted in this sequence.

It is remarkable that the two compatibility sequences shown in Figs. 1 and 7, which are based on entirely independent assumptions, are quite similar for most elements. The chief difference lies in the positions of the elements $\mathrm{Pb}, \mathrm{Nb}$ and $\mathrm{Ta}$. In addition, the concentrations of these elements in 
both continental and oceanic crust are anomalous in Fig. 7.

Fig. 8 shows the standard deviations of the MORB concentration averages plotted in the compatibility sequence given in Fig. 7. The decrease in variability with increasing compatibility is now much more nearly monotonic than in Fig. 2 . The slight negative anomalies for $\mathrm{Pb}, \mathrm{Sr}$, and $\mathrm{Eu}$ are probably caused by buffering of these elements during fractional crystallization (see previous section). All other anomalies (except for $\mathrm{Cu}$, which remains unexplained), may be ascribed to analytical uncertainties or uncertainties in the exact element sequence.

\section{The significance of $\mathrm{Pb}, \mathrm{Nb}$ and $\mathrm{Ta}$}

In the preceding sections it was shown that $\mathrm{Pb}$, when plotted in the compatibility sequence of Fig. 1 , has an anomalously low variability in MORB (Fig. 2), although its mean concentration is normal. If, on the other hand, the compatibility sequence is based on the data from the oceanic basalts themselves, then $\mathrm{Pb}$ has nearly normal variability (Fig. 8) but highly anomalous mean concentrations in both MORB and the continental crust (Fig. 7). Concentration anomalies are also evident for $\mathrm{Nb}$ and $\mathrm{Ta}$ in Fig. 7. * The differences in the two compatibility sequences and the anomalies just noted are not consistent with the assumption that these elements have the same partition coefficients in stages 1 and 2 .

The above observations suggest that lead is strongly depleted; but, unlike other highly depleted elements, it is comparatively uniformly distributed in the residual mantle. If the heterogeneous concentrations of the other highly depleted elements had been produced during the extraction of the continental crust (= stage 1 ), then the $\mathrm{Pb}$ concentrations should have been just as heterogeneous, and a special mechanism would have to have intervened to homogenize $\mathrm{Pb}$ but not the

\footnotetext{
* Ta is not plotted in this paper, because the estimated concentration in the continental crust of 1 ppm from [17] yields a ratio of $\mathrm{Nb} / \mathrm{Ta}=11$, which is inconsistent with observed $\mathrm{Nb} / \mathrm{Ta}$ ratios elsewhere, which appear to be uniform at $\mathrm{Nb} / \mathrm{Ta}=16-18$ [9]. For the purpose of the present paper, I assume that $\mathrm{Ta}$ has exactly the same normalized concentration as $\mathrm{Nb}$ in all reservoirs considered
}

other similarly depleted elements in the residual mantle. Convection combined with diffusion, the mechanism generally accepted to cause mixing, is incapable of such selective homogenization, because diffusion (the only homogenization process which might be element-selective) is effective only on a scale of centimeters.

Similar considerations have previously led the author [2] to the conclusion that all the incompatible elements in the residual mantle were fairly well homogenized or rehomogenized after the separation of the bulk of the continental crust. The present-day heterogeneities evident from the isotopic and elemental abundances of incompatible elements must have been created subsequently and without major involvement of the continental crust. Although the arguments were similar, the evidence used in [2] was in part independent, because it was based on the similarity of $\mathrm{Ce} / \mathrm{Pb}$ (and $\mathrm{Nb} / \mathrm{U}$ ) ratios in MORB and OIB rather than on the variability of the absolute concentrations within MORB.

The secondary differentiation is suggested to be the creation of the oceanic crust and lithosphere. It fractionated the residual mantle into a variably depleted N-type MORB mantle and a variably enriched P-type MORB and OIB mantle. During this differentiation, the partitioning behavior of $\mathrm{Pb}, \mathrm{Nb}$ and $\mathrm{Ta}$ was "oceanic" rather than "continental". Therefore, the concentration heterogeneities were produced during the second, "oceanic" stage, and this produced the regular pattern of standard deviation shown in Fig. 8. The absolute concentrations in MORB, on the other hand, are dominated by the first, "continental" stage. The additional changes in the average element concentrations resulting from the secondary differentiation are comparatively small because the complementary enriched (OIB source) reservoir is much smaller than the continental crust. In the context of the rough two-stage model, the effect of this additional differentiation on the mean concentrations of the other elements in MORB is negligible.

The switch in partitioning is illustrated in Fig. 9. $\mathrm{Nb}$ and $\mathrm{Ta}$ were moderately incompatible (similar to $\mathrm{Ce}$ and $\mathrm{Pr}$ ) during the extraction of the continental crust and became highly incompatible (similar to $\mathrm{U}$ and $\mathrm{K}$ ) during the extraction of MORB. Conversely, $\mathrm{Pb}$ was highly incompatible 


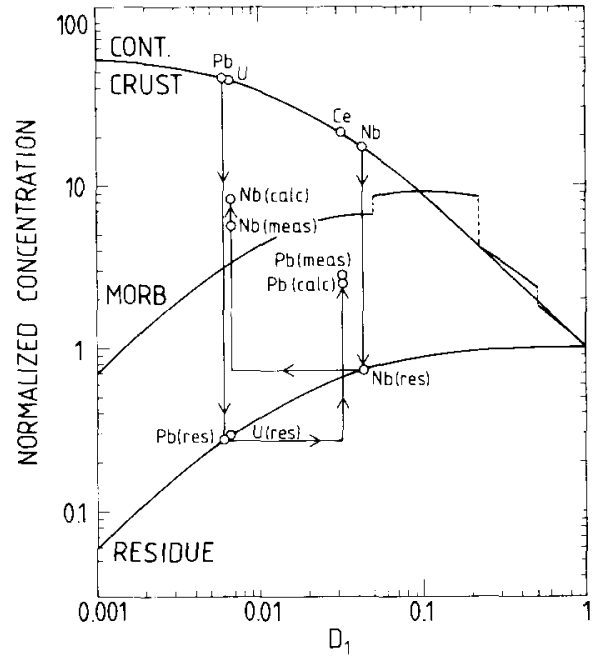

Fig. 9. Difference in partition coefficients between stage-1 ("continental melting") and stage-2 ("oceanic melting"). The arrows trace the process forward in time. They go from the concentration in the continental crust, which defines the partition coefficient $D_{1}$, to the point of intersection with the residual mantle. The shift in partition coefficient is shown by the horizontal portion, which ends at the location of the respective coefficient appropriate for MORB melting. This is defined by the position of $\mathrm{Ce}$ for $\mathrm{Pb}$, and $\mathrm{U}$ for $\mathrm{Nb}$ and $\mathrm{Ta}$, respectively (see Fig. 7). Each arrow ends at the concentration value in MORB, calculated from equation (5) as in Fig. 5. For comparison, the measured MORB averages from Table 1 are also shown.

(similar to Ba) during extraction of the continental crust and became moderately incompatible (similar to $\mathrm{Ce}$ ) during extraction of MORB. This explanation has previously been advanced [2] to explain the uniform but non-primitive $\mathrm{Ce} / \mathrm{Pb}$ and $\mathrm{Nb} / \mathrm{U}$ ratios in MORB and OIB. It provides a plausible rationale for the so-called lead paradox [30], as has already been noted [2,31].

The process is traced quantitatively in Fig. 9, using the specific melting model of Fig. 5. Starting with the continental $\mathrm{Pb}$ concentration estimate TM1 (see Table 1), for example, the Pb concentration in the residue is given by the intersection of the vertical arrow with the curve labeled "residue". The new partition coefficient appropriate for stage 2 is found from the position of $\mathrm{Ce}$, and the $\mathrm{Pb}$ concentration in MORB is calculated from equation (5) as in Fig. 5. The calculated $\mathrm{Pb}$ concentration in MORB is found to be quite similar to the measured MORB value from Table 1. A similar trace is shown for $\mathrm{Nb}$ and $\mathrm{Ta}$. The agreement between calculated and observed abundances in MORB is slightly poorer, but considering the simplifying assumptions, it is still surprisingly good.

The mantle evolution model proposed by Hofmann et al. [2] is consistent with all the observations noted above. It specifies that the residual mantle was homogenized during or after extraction of the bulk of the continental crust. The fractionation between MORB and OIB sources occurred subsequently and by a process which differed from continent formation in that it left the previously homogenized $\mathrm{Nb} / \mathrm{U}$ and $\mathrm{Ce} / \mathrm{Pb}$ ratios unchanged. The model also explains why the concentrations of $\mathrm{Nb}$ and $\mathrm{Ce}$ have similar variabilities as $U$ and $\mathrm{Pb}$, respectively: the heterogeneities of the present-day MORB source were not produced during the extraction of the continental crust but during the subsequent fractionation of the residual mantle into more or less depleted MORB and more or less enriched OIB sources. The chemistry of this latter fractionation process was apparently similar to the chemistry of present-day MORB production in that it fractionated many element ratios such as $\mathrm{Rb} / \mathrm{Sr}$, $\mathrm{Sm} / \mathrm{Nd}$, or $\mathrm{U} / \mathrm{Pb}$, but not the ratios $\mathrm{Nb} / \mathrm{U}$ and $\mathrm{Ce} / \mathrm{Pb}$. These observations reinforce the hypothesis $[32,33]$ that the chief mechanism responsible for causing the OIB source enrichment is the magmatic processes producing the oceanic crust.

The view of the mantle that emerges is that convection has erased most of the heterogeneities left in the residual mantle region when the main mass of the continental crust was formed. The heterogeneities observed in the present-day source regions of MORB and OIB are younger than the mean age of the continental crust. They were produced by the production of oceanic crust and lithosphere and returned to the mantle by subduction. In contrast, recycling of continental material plays only a very subordinate role in controlling mantle chemistry. The "oceanic" differentiation still continues on a large scale, and mantle convection has not yet erased the secondary heterogeneities thus created.

\subsection{Mineralogical causes of the compatibility} switch

Fig. 9 shows that $\mathrm{Nb}$ (together with $\mathrm{Ta}$, not shown) shifted to the left between stage 1 and stage 2, whereas $\mathrm{Pb}$ shifted to the right. What 
mineralogical mechanisms might have produced these shifts? Much speculation and some experimentation has been devoted to the negative $\mathrm{Nb}-\mathrm{Ta}$ anomaly found in nearly all continental rocks (Fig. 7) but also in all island arc volcanics, and a full review of this subject is beyond the scope of this paper. Ti-minerals such as rutile and ilmenite have high partition coefficients for $\mathrm{Nb}$ and $\mathrm{Ta}$ [34] and could hold these elements back in the mantle during subduction melting, but the solubility of $\mathrm{Ti}$ in mafic silicate melts is also so high that it is unlikely that these minerals could survive partial melting at reasonable melt fractions [35,36]. If Ti-minerals are indeed responsible for depleting the continental crust and enriching the residual mantle in $\mathrm{Nb}$ and $\mathrm{Ta}$, the transfer of those elements which are positioned to the left of $\mathrm{Nb}$ and $\mathrm{Ta}$ in Fig. 1 must occur predominantly by a mechanism other than the extraction of a mafic partial melt. Dehydration of the subducted oceanic crust may well be such a mechanism [37]. This would require that the titanium mineral(s) which hold $\mathrm{Nb}$ and $\mathrm{Ta}$ would not dissolve in the hydrothermal solution, but the solubilities of $\mathrm{Cs}$, $\mathrm{Rb}, \mathrm{K}, \mathrm{Th}, \mathrm{U}, \mathrm{Pb}$ and $\mathrm{La}$ would be high enough for an efficient transfer into the melting region to produce island arc magmas and ultimately continental crust. An alternative mechanism might be the extraction of a silicic partial melt from the subducted oceanic crust [38]. This melt would have a sufficiently low Ti solubility to keep rutile stable in the residue. It would intrude and modify the composition of the overlying mantle wedge, which in turn would yield the melts that actually reach the surface and ultimately produce new continental crust.

Another possibility that has not been sufficiently explored is the role of amphiboles in this transfer process. Partition coefficients for $\mathrm{Nb}$ and $\mathrm{Ta}$ are apparently higher than unity in some amphiboles [39,40], and if the separation of partial melt from its residue occurs within the stability field of such an amphibole, the negative $\mathrm{Nb}-\mathrm{Ta}$ anomaly could be produced by magmatic processes also. When the melting conditions are "dry" as is true for MORB, amphibole would not be present, and $\mathrm{Nb}$ and $\mathrm{Ta}$ would become highly incompatible.

The mineralogical mechanism for the shift in the partitioning of $\mathrm{Pb}$ is even less obvious. The highly incompatible behavior during stage 1 is consistent with the experimentally determined very low partition coefficient of $\mathrm{Pb}$ in clinopyroxene [41]. On the other hand, it seems unlikely that $\mathrm{Pb}$ could be as incompatible as Ba during purely magmatic processes, because its ionic radius is similar to that of $\mathrm{Sr}$ and significantly smaller than that of $\mathrm{Ba}$. Again, perhaps the solution lies in an enhanced hydrothermal transfer of $\mathrm{Pb}$ from the subducted slab to the overlying mantle.

The relatively compatible behavior of $\mathrm{Pb}$ during MORB melting might be related to the participation of plagioclase either during the partial melting or subsequent fractional crystallization. This inference is supported by the observation that the elements with unusually low variances in Fig. $2, \mathrm{~Pb}, \mathrm{Sr}$, and $\mathrm{Na}$, have relatively high partition coefficients in plagioclase. In Fig. 8, the effect is diminished but still discernible for $\mathrm{Pb}$ and $\mathrm{Sr}$. Further support comes from the slight negative Eu anomaly seen in average MORB $[4,42]$. Presnall and Hoover [43] and Klein and Langmuir [1] have suggested that residual plagioclase may be present in at least the upper portion of the melting mantle column producing MORB. Another possibility is that $\mathrm{Pb}$ may be retained by residual sulfide during MORB melting. This is suggested by the observation that MORB are usually saturated in sulfide, which buffers the sulfur concentration in MORB at about $1000 \mathrm{ppm}$ [44].

The "anomalous" continental concentrations seen in Fig. 7, namely low $\mathrm{Nb}$ and $\mathrm{Ta}$, and high $\mathrm{Pb}$, are characteristic of all types of island arc volcanics, even when these are depleted tholeiites otherwise similar to MORB, as well as in almost all types of continental rocks (except for some apparently hot-spot-related basalts). This strengthens the genetic link between subduction processes and the mechanism(s) that generate the continental crust, including the Archean crust, the origin of which remains controversial.

In summary, the specific mechanisms causing the special behavior of $\mathrm{Nb}, \mathrm{Ta}$, and $\mathrm{Pb}$ are not yet well understood. It seems clear that different mineral phases are responsible for the anomalous behavior of $\mathrm{Nb}$ and $\mathrm{Ta}$ on the one hand, and of $\mathrm{Pb}$ on the other. It is certainly not surprising that chemical elements exist which behave very differently in (presumably hydrous and relatively deepseated) subduction processes than in (compara- 
tively dry and shallow) ocean ridge processes. To this author, it is much more surprising that all the other chemical elements conform to the simple and complementary relationship displayed by Figs. 1 and 7.

\section{Conclusions}

Normalized element abundances in the continental crust have been contrasted with those in average MORB, which is taken to represent the oceanic crust. The two abundance patterns form a simple, complementary relationship which can be explained by a simple two-stage differentiation model of the mantle.

In the continental crust, the maximum normalized abundances of $C^{*}=40-80$ are realized by the most incompatible elements $\mathrm{Cs}, \mathrm{Ba}, \mathrm{Rb}, \mathrm{Th}$ and $\mathrm{U}$, which are strongly depleted in the residual mantle. The oceanic crust has an abundance maximum of $C^{*}=10$ for the moderately incompatible elements $\mathrm{Zr}, \mathrm{Hf}, \mathrm{Na}, \mathrm{Ti}$, and the heavy REE. These abundance maxima are used to constrain the effective melt fractions of the mantle melts that ultimately form both types of crust.

The apparent aggregate melt fraction is between 1 and $2 \%$ for the continental crust and about $10 \%$ for average MORB. Such comparatively low melt fractions are consistent with low abundances in MORB of $\mathrm{Ca}, \mathrm{Al}$, and $\mathrm{Sc}$ (relative to the heavy REE, $\mathrm{Zr}, \mathrm{Hf}$, and $\mathrm{Ti}$ ), which are best explained by the retention of residual clinopyroxene.

The simplicity of the abundance patterns and the model based on these abundances imply that the production of continental and oceanic crust are governed by similar bulk partition coefficients for most of the elements considered. Striking exceptions are $\mathrm{Nb}$ and $\mathrm{Ta}$, which are comparatively compatible during production of continental crust but highly incompatible during production of oceanic crust, and $\mathrm{Pb}$, which is highly incompatible during production of continental crust and much more compatible during production of oceanic crust. Because of this contrasting behavior, these elements are more discriminating indicators than $\mathrm{Nd}, \mathrm{Sr}$, or $\mathrm{Hf}$ isotopes for tracing possible recycling of either continental or oceanic crust into the mantle.
The batch melting equations used to construct the model are not meant to imply that the continental or oceanic crusts were actually produced by simple batch melting. Rather, they demonstrate that a satisfactory global mass balance exists for the chemistries of these crusts, the residual mantle, and the initial primitive mantle. Such a balance had previously been shown to exist only for the combined $\mathrm{Rb}-\mathrm{Sr}$ and $\mathrm{Sm}-\mathrm{Nd}$ abundances and isotopic compositions, and the results had been in apparent conflict with the isotopic data for $\mathrm{Pb}$. This conflict is resolved by the dual partitioning behavior of $\mathrm{Pb}$.

\section{Acknowledgements}

Early versions of this paper have circulated several years ago, and many people have made helpful comments on it. Of these I remember specifically Jon Patchett, Bill White and Catherine Chauvel, all of whom persuaded me to delete some of the more elaborate model calculations, and Claude Allègre who urged me to include the continental crust quantitatively. The more recent version of the paper has been reviewed by Bill McDonough, Ted Ringwood, Shen-Su Sun, K.H. Wedepohl, and Alan Zindler. I thank them all for catching mistakes and for their constructive criticism, which led to many important improvements and clarifications. I hope they will forgive me for not always following all points of their advice.

\section{References}

1 E.M. Klein and C.H. Langmuir, Global correlations of ocean ridge basalt chemistry with axial depth and crustal thickness, J. Geophys. Res. 92, 8089-8115, 1987.

2 A.W. Hofmann, K.P. Jochum, M. Seufert and W.M. White, $\mathrm{Nb}$ and $\mathrm{Pb}$ in oceanic basalts: new constraints on mantle evolution, Earth Planet. Sci. Lett. 79, 33-45, 1986.

3 S.R. Hart, Heterogeneous mantle domains: signatures and mixing chronologies, Earth Planet. Sci. Lett. 90, 273-296, 1988 (this issue).

4 K.P. Jochum, A.W. Hofmann, M. Seufert and W.M. White, The composition of mid-ocean ridge basalts, manuscript in preparation, 1988.

5 S.-S. Sun, R.W. Nesbitt and A.Y. Sharaskin, Geochemical characteristics of mid-ocean ridge basalts, Earth Planet. Sci. Lett. 44, 119-138, 1979.

6 S.R. Hart and A. Zindler, In search for a bulk-earth composition, Chem. Geol. 57, 247-267, 1986.

7 N.M. Evensen, P.J. Hamilton and R.K. O'Nions, Rare-earth abundances in chondritic meteorites, Geochim. Cosmochim. Acta 42, 1199-1212, 1978. 
8 H. Beer, G. Walter, P.J. Macklin and P.J. Patchett, Neutron capture cross sections and solar abundances of ${ }^{160,161} \mathrm{Dy}$, ${ }^{170,171} \mathrm{Yb},{ }^{175,176} \mathrm{Lu}$, and ${ }^{176,177} \mathrm{Hf}$ for the $s$-process analysis of the radio-nuclide ${ }^{176} \mathrm{Lu}$. Phys. Rev. C30, 464-478, 1984.

9 K.P. Jochum, H.M. Seufert, B. Spettel and H. Palme. The solar-system abundances of $\mathrm{Nb}, \mathrm{Ta}$, and $\mathrm{Y}$, and the relative abundances of refractory lithophile elements in differentiated planetary bodies, Geochim. Cosmochim. Acta 50, 1173-1183, 1986.

10 E. Anders and M. Ebihara, Solar-system abundances of the elements, Geochim. Cosmochim. Acta 46, 2363-2380, 1982.

11 H. Wänke, Constitution of terrestrial planets, Philos. Trans. R. Soc. London, Ser. A 303, 287-302, 1981.

12 K.P. Jochum, A.W. Hofmann, E. Ito, H.M. Seufert and W.M. White, K, U, and Th in mid-ocean ridge basalt glasses and heat production, $\mathrm{K} / \mathrm{U}$ and $\mathrm{K} / \mathrm{Rb}$ in the man. tle, Nature 306, 431-436, 1983.

13 A.W. Hofmann and W.M. White, $\mathrm{Ba}, \mathrm{Rb}$ and $\mathrm{Cs}$ in the Earth's mantle, Z. Naturforsch. 38a, 256-266, 1983.

14 W.F. McDonough, S.-S. Sun, A.E. Ringwood, E. Jagoutz and A.W. Hofmann, $\mathrm{Rb}$ and $\mathrm{Cs}$ in the Earth and Moon and the evolution of the Earth's mantle, Earth Planet. Sci. Lett., submitted, 1988

15 K.P. Jochum, A.W. Hofmann and H.M. Seufert, Siderophile Elemente in ozeanischen Basalten, ihre Verarmung im primitiven Mantel und ihre Bedeutung bei der Entwicklungsgeschichte der Erde, Fortschr. Mineral. 64, Beih. 1, 79, 1986.

16 S.-S. Sun, Chemical composition and origin of the earth's primitive mantle, Geochim. Cosmochim. Acta 46, 179-192, 1982.

17 S.R. Taylor and S.M. McLennan, The Continental Crust: Its Composition and Evolution, 312 pp., Blackwell, Oxford, 1985.

18 D.E. Hayes, Age-depth relationships and depth anomalies in the Southeast Indian Ocean and South Atlantic Ocean, $\mathbf{J}$. Geophys. Res. 93, 2937-2954, 1988.

19 D.A. Wood, J.-L. Joron, M. Treuil, M. Norry and J. Tarney, Elemental and $\mathrm{Sr}$ isotopic variations in basic lavas from Iceland and the surrounding ocean floor, Contrib. Mineral. Petrol. 70, 319-339, 1979.

20 D.M. Shaw, Trace element fractionation during anatexis, Geochim. Cosmochim. Acta 34, 237-243, 1970.

21 T.H. Green and N.J. Pearson, Rare earth element partitioning between clinopyroxene and silicate liquid at moderate to high pressures, Contrib. Mineral. Petrol. 91, 24-36, 1985.

22 N.M. Ribe, Dynamical geochemistry of the Hawaiian plume, Earth Planet. Sci. Lett. 88, 37-46, 1988.

23 M.J. O'Hara, Geochemical evolution during fractional crystallisation of a periodically refilled magma chamber, Nature 266, 503-507, 1977.

24 M.J. O'Hara and R.E. Mathews, Geochemical evolution in an advancing, periodically replenished, periodically tapped, continuously fractionated magma chamber, J. Geol. Soc. London 138, 237-277, 1981.

25 G.L. Ray, N. Shimizu and S.R. Hart, An ion probe study of the partitioning of trace elements between clinopyroxene and liquid in the system diopside-albite-anorthite, Geochim. Cosmochim. Acta 47, 2131-2140, 1983.

26 H.J.B. Dick and R.L. Fisher, Mineralogical studies of the residues of mantle melting: abyssal and Alpine-type peri- dotites, in: Kimberlites II. The Mantle and Crust-Mantle Relationships, J. Kornprobst, ed., pp. 295-308, Elsevier, Amsterdam, 1984.

27 P.J. Michael and E. Bonatti, Peridotite composition from the North Atlantic: regional and tectonic variations and implications for partial melting, Earth Planet. Sci. Lett. 73 , 91-104, 1985.

28 S.-S. Sun and R.W. Nesbitt, Chemical heterogeneity of the Archaean mantle, composition of the earth and mantle evolution, Earth Planet. Sci. Lett. 35, 429-448, 1977.

29 W.B. Bryan, G. Thompson and J.N. Ludden, Compositional variation in normal MORB from $22^{\circ}-25^{\circ} \mathrm{N}$ : MidAtlantic Ridge and Kane Fracture Zone, J. Geophys. Res. 86, 11815-11836, 1981.

$30 \mathrm{C} . J$. Allègre, Comportement des systèmes U-Th- $\mathrm{Pb}$ dans le manteau supérieur et modèle d'évolution de ce dernier au cours de temps géologiques, Earth Planet. Sci. Lett. 5, 261-269, 1969.

31 H.E. Newson, W.M. White, K.P. Jochum and A.W. Hofmann. Siderophile and chalcophile element abundances in oceanic basalts, $\mathrm{Pb}$ isotope evolution and growth of the Earth's core, Earth Planet. Sci. Lett. 80, 299-313, 1986.

32 A.W. Hofmann and W.M. White, The role of subducted oceanic crust in mantle evolution, Carnegie Inst. Washington Yearb. 79, 477-483, 1980.

33 A.W. Hofmann and W.M. White, Mantle plumes from ancient oceanic crust, Earth Planet. Sci. Lett. 57, 421-436, 1982.

34 T.H. Green and N.J. Pearson, An experimental study of Nb and $\mathrm{Ta}$ partitioning between $\mathrm{Ti}$ rich minerals and silicate liquids at high pressure and temperature, Geochim. Cosmochim. Acta 51, 55-62, 1987

35 T.H. Green and N.J. Pearson, Ti-rich accessory phase saturation in hydrous mafic-felsic compositions at high $P$, $T$, Chem. Geol. 54, 185-201, 1986.

36 F.J. Ryerson and E.B. Watson, Rutile saturation in magmas: implications for $\mathrm{Ti}-\mathrm{Nb}-\mathrm{Ta}$ depletion in island-arc magmas, Earth Planet. Sci. Lett. 86, 225-239, 1988

37 A.E. Ringwood, The petrologic evolution of island are systems, J. Geol. Soc. London 130, 183-204, 1974.

38 A.E. Ringwood, personal communication, $1987 / 88$.

39 J.A. Pearce and M.J. Norry, Petrogenic implications of Ti, $\mathrm{Zr}, \mathrm{Y}$, and $\mathrm{Nb}$ variations in volcanic rocks, Contrib. Mineral. Petrol. 69, 33-47, 1979.

40 F. Lemarchand, B. Villemant and G. Calas, Trace element distribution coefficients in alkaline series, Geochim. Cosmochim. Acta 51, 1071-1081, 1987.

41 E.B. Watson, D. Ben Othman, J.-M. Luck and A.W. Hofmann, Partitioning of $\mathrm{U}, \mathrm{Pb}, \mathrm{Cs}, \mathrm{Yb}, \mathrm{Hf}, \mathrm{Re}$ and $\mathrm{Os}$ between chromian diopsidic pyroxene and haplobasaltic liquid, Chem. Geol. 62, 191-208, 1987.

42 A.W. Hofmann, K.P. Jochum and W.M. White, MORB-enrichment in RTF-magma chambers (abstract), EOS, Trans. Am. Geophys. Union 66, 406, 1985.

43 D.C. Presnall and J.D. Hoover, High pressure phase equilibrium constraints on the origin of mid-ocean ridge basalts, in: Magmatic Processes: Physiochemical Principles, B.O. Mysen, ed., Geochem. Soc., Spec. Publ. 1, 75-89, 1987.

44 E.A. Mathez, Sulfur solubility and magmatic sulfides in submarine basalt glass, J. Geophys. Res. 81, 4269-4276, 1876. 